\title{
A IMPORTÂNCIA DA CONTROLADORIA NA GESTÃO ORGANIZACIONAL
}

\author{
Francine Dantas Pardo, Eduardo Teraoka Tofoli
}

Universidade do Oeste Paulista - UNOESTE, MBA em Finanças e Controladoria, Presidente Prudente, SP. E-mail: fran.pardo@hotmail.com

\section{RESUMO}

A competitividade e a variedade de produtos e serviços oferecidos no mercado atual faz com que seja necessário que haja um planejamento e um controle de forma mais eficiente nas empresas, surgindo assim à controladoria para auxiliar na gestão organizacional. A partir dessa perspectiva o objetivo desse trabalho foi de verificar a importância da controladoria para a gestão organizacional, analisando o conceito de controladoria e gestão organizacional, verificando a relação de controladoria com a criação de estratégias e planejamentos empresariais com o enfoque nos benefícios que a controladoria traz para empresa. Portanto foi realizada uma pesquisa exploratória de abordagem qualitativa a partir de levantamentos bibliográficos com base em material já elaborado e com a consulta em livros e autores que já se aprofundaram em assuntos semelhantes. Contudo pode-se observar que a controladoria é essencial para qualquer empresa, acompanhando a avaliação dos resultados e dando suporte para a tomada de decisão.

Palavras-Chave: Controladoria, Gestão Organizacional, Planejamento, Estratégia, Resultados.

\section{THE IMPORTANCE OF CONTROLLERSHIP IN ORGANIZATIONAL MANAGEMENT}

\section{ABSTRACT}

The competitiveness and the variety of products and services offered in the current market means that it is necessary that there is a more efficient planning and control in the companies, thus appearing to the controller to assist in the organizational management. From this perspective, the objective of this work was to verify the importance of controlling for organizational management, analyzing the concept of control and organizational management, verifying the relationship of control with the creation of strategies and business plans with the focus on the benefits that the controller Brings to company. Therefore, an exploratory qualitative approach was carried out based on bibliographical surveys based on already prepared material and with the consultation in books and authors that have already delved into similar subjects. However, it can be observed that the control is essential for any company, accompanying the evaluation of results and supporting decision making.

Keywords: Controllership, Organizational Management, Planning, Strategy, Results

\section{INTRODUÇÃO}

A atual competitividade das empresas, as constantes alterações no mundo dos negócios e o avanço da tecnologia da informação faz com que seja necessária uma gestão eficiente, onde as empresas precisam estar sempre se atualizando e melhorando as ferramentas de gestão, desse modo surge a controladoria que é uma ferramenta utilizada como suporte de planejamento e tomada de decisão, pois atua na otimização dos recursos, visando melhor desempenho em todas as áreas da organização.

A controladoria fornece informações para que seja feito um planejamento adequado, onde o planejamento torna-se fundamental para uma boa gestão organizacional, fazendo com que as organizações possam estar sempre em uma posição de competitividade, pois possibilita a análise do ambiente de uma organização favorecendo a criação de uma visão sobre as oportunidades e 
ameaças, bem como a percepção dos pontos fortes e fracos. Neste sentido também é importante que a empresa esteja bem definida em relação ao seu propósito. O propósito é importante para saber onde a organização deseja chegar, quais os objetivos que deverão ser alcançados.

Para Oliveira $(2009$, p.16) "a área de controladoria surge da necessidade de otimizar os resultados das decisões que são tomadas com referência à empresa". Uma premissa para a sua existência é a de que a ciência contábil tem o instrumental adequado para o controle empresarial e para a otimização do resultado de entidades econômicas.

Desta forma a controladoria como ferramenta de gestão organizacional é essencial para o funcionamento de uma empresa, pois atua como ferramenta otimizadora, buscando sempre o melhor resultado, estando presente desde a fase do planejamento até a execução e controle das atividades empresariais.

Com isso, o objetivo desse estudo foi de verificar a importância da controladoria na gestão organizacional.

\section{METODOLOGIA}

A pesquisa tem por objetivo verificar a importância da controladoria na gestão organizacional. Para isso foi feito uma pesquisa qualitativa onde "busca-se descrever a complexidade de uma hipótese ou problema, analisar a interpretação de certas variáveis, compreender e classificar processos dinâmicos experimentados por grupos sociais" (OLIVEIRA, 2007, p. 117).

A presente pesquisa se caracteriza como exploratório, na medida que por meio desse estudo, busca-se conhecer com maior profundidade o assunto de modo a torná-lo mais claro ou construir questões importantes para a condução da pesquisa.

Gil (2002) destaca que a pesquisa exploratória é desenvolvida no sentido de proporcionar uma visão geral acerca de determinado fato. Portanto, esse tipo de pesquisa é realizado, sobretudo, quando o tema escolhido é pouco explorado e torna-se difícil formular hipóteses precisas e operacionalizáveis.

Para que tal pesquisa fosse bem elaborada foi necessária a consulta a livros e autores que já se aprofundaram em assuntos semelhantes, com a intenção de levar ao leitor maiores conhecimentos sobre assunto. Assim foi realizada uma pesquisa bibliográfica, a qual segundo Vergara (2004, p. 48) "é o estudo sistematizado desenvolvido com base em material publicado em livros, revistas, jornais, redes eletrônicas, isto é, material acessível ao público em geral".

De acordo com Marconi e Lakatos (1996, p. 66), a pesquisa bibliográfica "oferece meios para definir, resolver não somente problemas já conhecidos, como também explorar novas áreas onde os problemas não se cristalizaram suficientemente".

\section{JUSTIFICATIVA}

Para que as organizações possam desenvolver suas atividades permitindo a avaliação e o controle do desempenho das organizações e tomar decisões estratégicas, faz-se necessário obter informações por meio da controladoria.

A controladoria consiste em manter um controle intenso e organizado sobre determinado órgão ou departamento da empresa. Ou seja, é o controle das atividades desenvolvidas, no qual gera informações sobre o resultado obtido nas operações comparando-os com os resultados planejados, permitindo assim a avaliação do desempenho dos gestores, das áreas, análise dos resultados dos produtos e serviços e a tendência de comportamento futuro da organização (OLIVEIRA, 2009).

Segundo Nakagawa (1993), a controladoria organiza e reporta os dados relevantes, exerce força ou influência, o que incentiva os gestores tomarem decisões lógicas e consistentes com a missão e objetivos da organização. 
A controladoria contribui para uma organização da qual faça parte ao desempenhar atividades como: "colaborar na formação das estratégias, organizar, analisar e apresentar dados coletados, elaborar informações relevantes à administração e gerar modelos decisórios coerentes e consistentes com a missão e visão da empresa " (OLIVEIRA, 2009, p.16).

A partir dessas definições, pode-se entender que o papel da controladoria é cuidar pelo bom desempenho da empresa, administrando as atividades existentes entre os diversos departamentos em busca do maior grau da eficácia empresarial, onde a controladoria consegue obter informações internas e externas, que podem ser importantes para a tomada de decisão, fazendo com que a organização consiga atingir o seu objetivo de forma mais eficiente, evitando desperdícios desnecessários.

A chamada gestão organizacional nada mais é do que a administração de um negócio, empresa ou organização com o objetivo de alcançar metas e conquistar resultados positivos e rentáveis.

Padoveze e Benedicto (2003) salientam que, como o modelo de gestão é a base para formatação de todo o processo de gestão, este, por sua vez, traduzirá em todas as suas etapas a cultura organizacional da empresa. O processo de gestão visa garantir que as decisões dos gestores contribuam para otimizar o desempenho da organização.

Assim, para obter uma gestão organizacional eficiente, a controladoria deve ser utilizada como ferramenta de assegurar as informações para tomada de decisão, usando o controle como uma etapa do processo administrativo, por meio do qual se busca garantir a continuidade da empresa pela adoção de medidas que consigam corrigir os problemas encontrados, em função dos erros observados, e pela elaboração das metas pretendidas, em decorrência das modificações observadas no ambiente interno e externo (OLIVEIRA, 2009).

Na visão de Fischmann (1991), planejar é antecipar o futuro, envolve definir um futuro desejado e os meios para alcançá-los. Sendo assim, torna-se necessário para a controladoria a existência de um processo estruturado de gestão na forma de planejamento estratégico, planejamento tático, planejamento operacional e controle.

Segundo Bognar (1991) o planejamento estratégico está direcionado para a definição do negócio em que a empresa está ou estará, e o tipo de empresa que é ou será, isto é, seus objetivos, para tanto, são explicitadas as estratégias, definidas de forma ampla e global, que irão suportar a consecução destes objetivos.

De modo geral a estratégia empresarial tem como principais características a determinação de metas qualitativas, metas quantitativas e metas integradas e o conjunto de decisões, objetivos e políticas a serem adotadas para que tais metas sejam atingidas. A estratégia, no contexto do ambiente corporativo, é a determinação de metas básicas a longo prazo e dos objetivos de uma empresa, bem como a adoção das linhas de ação e aplicação dos recursos necessários para alcançar essas metas (OLIVEIRA; PEREZ Jr; SILVA, 2015).

Para ter um Planejamento Estratégico eficiente é necessário que a organização tenha definido qual a missão que dará rumo para o funcionamento da empresa. Segundo Oliveira; Perez Jr; Silva (2015) determinar a missão de uma entidade é a primeira e talvez mais crítica etapa da elaboração do Planejamento Estratégico, uma vez que ela atua como referência na orientação de todo processo de planejamento empresarial e decisório em seu sentido mais amplo.

Os benefícios gerados pela gestão da controladoria são muitos, principalmente pela confiabilidade das informações que permitem melhorar os resultados e ajudar os gestores para que tomem melhores decisões na empresa.

Segundo Lunkes e Schnorrenberger (2009), os benefícios da controladoria é facilitar a interação na organização por meio da coordenação. Para tanto, é necessário à visão sistêmica, fazendo com que as organizações alcancem as metas e os resultados desejados. A controladoria 
ainda promove uma transparência nos processos de gestão e um envolvimento efetivo entre os gestores, a fim de minimizar os riscos e promover o melhor para a organização.

Segundo Christo (2008), a controladoria pode trazer muitos benefícios para as empresas, como:

a) Criar estratégias comerciais para encaminhar mercadorias paradas no estoque há muito tempo;

b) Efetuar um controle do mercado externo para analisar fatores de impacto;

c) Controlar semanalmente o planejamento orçamentário, oferecendo soluções para chegar o mais próximo possível das metas do orçamento;

d) Oferecer atendimento à diretoria através de controles atualizados (planilhas, relatórios, informativos de alertas);

e) Oferecer respostas consistentes as dúvidas da alta direção.

Dessa forma, nota-se que o setor da controladoria nas organizações é de extrema importância, pois através das análises geradas, contribuem para direcionar as empresas em quais rumos devem seguir, garantindo o sucesso, o aumento da lucratividade e a sobrevivência mercadológica, ou seja, maximiza as oportunidades e minimiza os problemas (OLIVEIRA, 2009).

\section{DISCUSSÃO}

A evolução dos processos transacionais e as mudanças no ambiente de negócios percebidas nos últimos anos impactaram diretamente na função da controladoria. A principal mudança surgiu com o rápido avanço tecnológico da área de sistemas e de computação (SCHIMIDT, SANTOS, 2009).

Hoje em dia, é corrente que as atividades de gestão da tecnologia de informação fiquem sob a responsabilidade da controladoria. Além dessa responsabilidade, a função de auditoria interna, gestão de risco e de controles e de auditoria de sistemas passou a ser direcionada para a área de controladoria. (SCHMIDT; SANTOS, 2009).

Com o avanço tecnológico a controladoria consegue usar as informações para trazer maiores benefícios para as organizações, auxiliando na tomada de decisão dos gestores, fazendo com que consigam estar mais próximos das metas e objetos traçados pela entidade.

De acordo com Figueiredo; Caggiano, (2008) a Controladoria tornou-se importante, pois o aumento da complexidade na organização das empresas, o maior grau de interferência governamental por meio de políticas fiscais, a diferenciação das fontes de financiamentos das atividades, a percepção das necessidades de consideração dos padrões éticos na condução dos negócios e, principalmente, a demanda por melhores práticas de gestão, criando a necessidade de um sistema contábil mais adequado para um controle gerencial mais efetivo, têm sido, entre outras, algumas das razões para que a responsabilidade com o gerenciamento das finanças das empresas tenha aumentado de importância dentro do processo de condução dos negócios.

A esse respeito, Oliveira (2009, p. 2) escreveu que "a controladoria, fornecedora de informações úteis à tomada de decisão, para a escolha de alternativas ótimas, entendidas como aquelas que mais valor adicionam ao negócio", é diretamente afetada por essas mudanças ambientais e pelos novos cenários com suas oportunidades e ameaças.

Com isso, os benefícios que a empresa pode ter na ação da controladoria, é a avaliação dos resultados econômicos para que sejam atingidos os objetivos e, também, assegurar a continuidade da empresa no mercado.

Deste modo, pode-se observar que a controladoria é essencial para uma gestão eficiente, estando diretamente ligada a todos os departamentos da organização.

\section{CONCLUSÃO}


As constantes alterações no mundo dos negócios, marcada pela globalização, pelo avanço tecnológico e a competitividade entre as empresas, traz a controladoria como departamento essencial para uma organização, onde através da controladoria pode-se obter informações precisas e confiáveis, que conduzem há uma gestão mais eficiente.

Entende-se que para ter sucesso com a controladoria, a organização necessita de ter metas pré-definidas, para que seja possível realizar um planejamento com foco no resultado que se pretende atingir, utilizando estrategicamente as informações geradas pelo departamento.

Com isso, as empresas modernas e que se preocupam com um processo de gestão bem desenvolvido, necessitam de uma estrutura organizacional bem delineada para a sua sobrevivência. Neste novo cenário surge um órgão interno cuja finalidade é garantir que as informações sejam adequadas ao processo decisório e que esteja sempre pronta a apoiar a diretoria da entidade no processo de gestão, a controladoria.

Dessa forma, podemos verificar a importância da controladoria para a gestão organizacional, onde a mesma tem papel fundamental no resultado da entidade, tendo a qualidade e veracidade da informação essências para o sucesso da controladoria e da organização, tornando a controladoria com departamento indispensável para qualquer empresa, atingindo assim, o objetivo desse trabalho.

A necessidade de manter a empresa sempre competitiva exige uma equação que une produtividade e eficiência, à alta lucratividade a custos menores, então, uma função que antes era apenas de suporte, passa a ter uma importância estratégica para as empresas.

\section{REFERÊNCIAS BIBLIOGRÁFICAS}

CHRISTO, R. B. Importância e benefícios da controladoria. Disponível em http://quantumtecnologia.blogspot.com.br/2008/10/importncia-e-benefciosdacontroladoria.html>Acesso em:24/04/2017.

FIGUEIREDO, Sandra, CAGgIANO, Paulo Cesar. Controladoria: Teoria e Prática, 4 ed. Atlas, $10 / 2008$.

FISCHMANN, A.A. Palestra proferida na USP. (Dissertação de Mestrado em Controladoria). São Paulo: USP, 1991.

GIL, A. C. Como elaborar projetos de pesquisa. 4 ed. São Paulo: Atlas, 2002.

LUNKES, R. J; SCHNORRENBERGER, D. Controladoria na coordenação dos sistemas de gestão. São Paulo: Atlas, 2009.

MARCONI, M.de A, LAKATOS, E. M. Técnicas de pesquisa. 3 ed. São Paulo: Atlas, 1996.

NAKAGAWA, M. Introdução à controladoria: conceitos, sistemas e implementação. São Paulo: Atlas, 1993.

OLIVEIRA, A. B. S. Controladoria: fundamentos do controle empresarial. São Paulo: Saraiva, 2009. OLIVEIRA, A. S. Controladoria. Saraiva, 06/2009.

OLIVEIRA, L. de, PEREZ Jr., J. H.; SILVA, C.A.S. Controladoria Estratégica - Textos e Casos Práticos com Solução, 11 ed. Atlas, 11/2015 
PADOVEZE, C. L.; BENEDICTO, G. C. Cultura organizacional: análise e impactos dos instrumentos no Processo de gestão. Atibaia, 2003

SCHMIDT,P.;SANTOS, J.L. Fundamentos de Controladoria. Atlas, São Paulo, 2009.

VERGARA, S. C. Projetos e relatórios de pesquisa em administração. 5 ed. São Paulo: Atlas, 2004. 